\title{
Organizational Change, New Information and Communication Technologies and the Demand for Labor in Services*
}

\author{
Martin Falk ${ }^{\dagger}$
}

May 3, 2001

\begin{abstract}
Between 1993 and 1995, the majority of German firms in services introduced new organizational practices (OC), in particular total quality management systems, certified ISO 9000, lean administration, flatter hierarchies, delegation of authority and ICT-enabled organizational changes). This paper analyzes the impact of organizational change as well as the impact of the introduction of information and communication technology (ICT) on actual labor demand as well as on employment expectations. The focus of attention is also directed to potential endogeneity of OC using treatment effect models as well as multivariate probit models. The empirical results suggest that OC has a positive effect on actual employment growth given output and factor price changes. Furthermore, we find that organizational change has a positive impact on expected employment for all skill groups except for unskilled labor. New ICT and the share of training expenditures are primary forces behind OC. Finally, employment effects are robust to endogeneity of organizational change.
\end{abstract}

Keywords: organizational change, ICT, skill structure

JEL Classification: J23, O33

*I have benefited from helpful suggestions by seminar participants at the IZA workshop 'Organizational Change and its Implications for the Labor Market' as well as the EALE/SOLE 2000 conference. Furthermore, I thank Herbert Buscher for helpful comments as well as Sandra Kneile for proof-reading.

${ }^{\dagger}$ Center for European Economic Research, L7,1, D-68161 Mannheim; phone: (0621) 1235153; fax: (0621) 1235-225; e-mail: falk@zew.de 


\section{Introduction}

Between 1993 and 1995, the majority of German service firms introduced new organizational practices or changed the organizational structure (OC) of the firm as well as introduced new information and communication technologies (ICT). Among the most important types of organizational change are total quality management systems, ISO 9000 followed by lean administration including flatter hierarchies and decentralization of decision-making. ${ }^{1}$ Furthermore, a substantial fraction of the firms reported that the most significant type of organizational change are ICT-enabled organizational changes, i.e., software for planning, order processing, controlling, logistics as well as internal and external connection of computers.

A number of factors contribute to the rising spread of new organizational practices. New breakthroughs in ICT have made it profitable for firms to introduce new organizational practices such as flatter hierarchies and to allow for greater decentralization of decision-making (see Lindbeck and Snower 1996, 2000). Furthermore, empirical studies found that the most important determinants of OC are formal and informal training as well as the introduction of ICT (OECD 1999, Batt 1999, Lynch and Black 1995). For instance, Lynch and Black (1995), using 1994 data for 1620 manufacturing and 1324 non-manufacturing firms, found that firms implementing high performance work organizations (HPWOs) practices are more likely to offer formal training programs. Brynjolfsson and Hitt (1998) suggested that decentralized work practices are often correlated with increased use of ICT.

It is well known that new organizational practices and new ICT create jobs which require a different skill level. On the theoretical side Bresnahan (1999) as well as Snower (1999) present a theoretical analysis of the impact of the expansion of ICT as well as of organizational change on the qualification structure of the workforce. Bresnahan (1999) suggested that ICT-enabled changes in work organizations may be more important than the direct effects of computers on employment change. The link between organizational changes and the demand for skilled labor has been empirically analyzed by a number of studies. For France, the UK and the U.S. several empirical studies provide evidence that organizational change may be attributed to the shift in demand towards skilled labor (see Bresnahan, Brynolfsson and Hitt 2001, Caroli and Van Reenen 2001, Caroli, Greenan

\footnotetext{
${ }^{1}$ ISO 9000 and related standards set the basic rules for quality systems - from concept to implementation.
} 
and Guellec, 2001). For the UK and France, Caroli and Van Reenen (2001) found that the past adoption of new organizational practices reduces the future employment of unskilled workers. For U.S. firms Bresnahan et al. (2001) found that skills and organizational practices are complementary. Caroli et al. (2001) found that organizational change has a significantly negative impact on operatives, whereas there is a negative but insignificant effect on the two upper skill levels. In contrast to these studies, Osterman (2000), using a representative sample between 230 and 400 U.S. firms with 50 or more employees, found that a initial high penetration of HPWOs is associated with a reduction of managerial employment as well as contingent workers during the period 1992 to 1997. For Germany, however, few empirical studies on the connections between organizational change and the labor market are available. One exception is Bauer and Bender (2000) who study the impact of organizational change on wages based on a linked employer-employee data set.

This paper provides further evidence on the relationship between the past introduction of new organizational practices as well as new ICT and future employment growth. In particular, we investigate the effect of different types of organizational change on actual employment growth. In order to proxy actual employment growth by educational qualifications we also use employment plans for different skill levels. This paper extends the previous literature in the following ways. First, in order to ensure that our results are not affected by potential endogeneity of organizational change in the labor demand equation, a selection equation explaining organizational change is added to the labor demand model. Previous theoretical and empirical research suggests that organizational change is more likely in firms with higher investment in training and human capital as well as a higher skill intensity of the firm. Egger and Grossmann (2000), for example, show that the increased availability of skilled workers creates incentives to introduce or increase the delegation of decision rights. Since the ratio of training expenditures to total wage costs does not directly affect labor demand, it is used as a identifying variable. Second, our sample does not suffer from any large firm biases. Third, we also study the effect of different types of organizational change on employment. To date few studies addressed the question whether different types of organizational change such as quality management systems contribute to employment growth. The data is drawn from the first and second wave of the Mannheim Service Innovation panel (ZEW-MIP).

The layout of the paper is the following. Section 2 outlines the empirical model as well as the hypotheses. Descriptive statistics and data used for the study are 
discussed in section 3. Section 4 presents the empirical results. Section 5 gives the conclusions.

\section{Empirical labor demand model at the firm level}

\subsection{Determinants of actual employment growth}

To examine the relationship between actual employment growth and organizational change, a standard conditional labor demand function based on a value added output function is derived:

$\Delta \ln L_{i}=\beta_{0}+\beta_{1} \Delta O C_{i}+\beta_{2} \Delta I C T_{i}+\beta_{3} \Delta \ln \left(W_{i} / P_{i}\right)+\beta_{4} \Delta \ln \left(Y_{i} / P_{i}\right)+\alpha X_{i}+\varepsilon_{i}$

where i denote firms and the variables are denoted as:

$\begin{array}{ll}\Delta \ln L_{i} & \text { average annual percentage change in employment between '94-96 } \\ \Delta O C_{i} & \text { introduction of new organizational practices between '93-95 (0/1) } \\ \Delta I C T_{i} & \text { new ICT in the production process between '93-95 (0/1) } \\ \Delta \ln \left(W_{i} / P_{i}\right) & \text { average annual percentage change in the total wage costs } \\ & \text { per employee deflated by } P_{i}, ' 94-96 \\ P_{i} & \text { industry specific gross output deflator } \\ \Delta \ln \left(Y_{i} / P_{i}\right) & \text { annual average percentage change in sales deflated by } P_{i},{ }^{\prime}, 94-96\end{array}$

Vector of other explanatory variables, $X_{i}$ :

$L_{H i} / L_{i} \quad$ share of high-skilled workers in total employment, 1994

$T R_{i} / W C_{i} \quad$ training expenditures in percent of total wage costs, 1994

$I C T_{i} / W C_{i} \quad$ ICT-investment in percent of total wage costs, 1994

size, sector and other control variables, 1994

The average annual percentage change in total employment is $\Delta \ln L_{i}$ which is assumed to depend linearly on the percentage change in output at constant prices, $\Delta \ln \left(Y_{i} / P_{i}\right)$, the percentage change in real wages, $\Delta \ln \left(W_{i} / P_{i}\right)$ and a vector of firm characteristics $X_{i}$. The key variables are the introduction of new organizational practices, $\triangle O C_{i}$, measured as a dummy variable indicating whether organizational change is introduced as well as the new information and communication technologies in the production process, $\triangle I C T$.

The introduction of new organizational practices is not exogenous to the firm. The usual determinants of organizational change are the skill level, adoption of 
new ICT or ICT intensity, competition indicators and firm size. Firms with a share of skilled workers are more likely to introduce organizational changes (Caroli et al. 2001). In order to take into account the potential endogeneity of organizational change in the labor demand equation, we estimate a treatment effects model of the following form (see Barnow, Cain and Goldberger 1981):

$\Delta \ln L_{i}=\beta_{0}+\beta_{1} \Delta O C_{i}+\beta_{2} \Delta I C T_{i}+\beta_{3} \Delta \ln \left(W_{i} / P_{i}\right)+\beta_{4} \Delta \ln \left(Y_{i} / P_{i}\right)+\alpha X_{1 i}+\varepsilon_{i}$

$$
\Delta O C_{i}^{*}=\delta_{1} X_{1 i}+\delta_{2} X_{2 i}+v_{i}
$$

where the observed decision is $\Delta O C_{i}=1$ if $\Delta O C^{*}>0$ and $\triangle O C_{i}=0$ otherwise. $X_{2 i}$ is a vector of identifying variables and $X_{1 i}$ includes the remaining exogeneous variables. The two-equation model is identified by inclusion in the selection equation variables, $X_{2 i}$, that may affect the decision to introduce new organizational practices but which may not directly affect employment growth. Preliminary regressions indicate that the ratio of training expenditure to total wage costs may serve as an identifying variable. $X_{1 i}$ contains firm characteristics such as new ICT and the skill intensity of the firm. The error terms $v_{i}$ and $\varepsilon_{i}$ are the errors of the employment equation and the selection equation. Both are assumed to be normal with mean zero and covariance matrix $\Omega$. The endogeneity of organizational change means that the error term in equation 2.2 is correlated with that in equation 2.3. In the empirical section we test this hypothesis. The treatment effects model can be estimated using either a two-step estimator or a full information maximum-likelihood estimator.

\subsection{Determinants of expected heterogeneous employment growth}

\subsubsection{Ordered probit model}

One aim of the paper is to examine the employment effects of organizational change when employment is disaggregated by different skill levels. Since a large number of employment growth rates for medium- and unskilled labor are either missing or appear unreliable, we use expected developments in employment by the skill level in order to proxy actual employment growth. ${ }^{2}$ The advantage of the categorical data is that the number of observations with about 1500 is quite large.

\footnotetext{
${ }^{2}$ The sample size due to missing information of each skill level reduces by one half.
} 
The disadvantage, however, is that categorical data are informationally less rich than continuous data. To estimate the employment effects of past OC we chose to use single equation ordered probit models. ${ }^{3}$

Let $\Delta L_{j, t+1}^{*}$ denote the unobserved index of expected employment change of skill level j. Define

$$
\Delta L_{j, t+1}^{*}=\alpha_{j 1} \Delta O C_{t}+\alpha_{j 2} \Delta I C T_{t}+\beta_{j}^{\prime} X_{t}+u_{j t}(j=1,2, \ldots, 5, t=1)
$$

where:

$\Delta L_{j, t+1}=0$ if $\Delta L_{j, t+1}^{*} \leq \mu_{j 0}, \Delta L_{j, t+1}=1$, if $\mu_{j 0}<\Delta L_{j, t+1}^{*} \leq \mu_{j 1}, \Delta L_{j, t+1}=2$, if $\mu_{j 1}<\Delta L_{j, t+1}^{*} \leq \mu_{j 2}, \Delta L_{j, t+1}=3$, if $\mu_{j 2}<\Delta L_{j, t+1}^{*} \leq \mu_{j 3}, \Delta L_{j, t+1}=4$, if $\Delta L_{j, t+1}^{*}>\mu_{j 4}$. The highest ranking represents strong increasing employment of skill category $\mathrm{j}$, while the lowest represents strong downward employment. The skill category $\mathrm{j}$ in which $\Delta L_{j, t+1}^{*}=\left(\Delta L_{H 1}^{*}, \Delta L_{H 2}^{*}, \Delta L_{M 1}^{*}, \Delta L_{M 2}^{*}, \Delta L_{U}^{*}\right)$ falls indicates the employment expectations for university graduates (two types), $\Delta L_{H 1}$, and $\Delta L_{H 2}$, masters and technicians, $\Delta L_{M 1}$, workers with a certificate from the dual vocational system, $\Delta L_{M 2}$, and unskilled workers, $\Delta L_{U}$, corresponding to the $\mathrm{j}$-th equation. The time period of the categories is a three year interval between 1995 and 1997. $X_{t}=\left(X_{1 t}, X_{2 t}, \ldots, X_{k t}\right)^{\prime}$ is the $(k \times 1)$ vector of other explanatory variables at time t (mainly for the year 1994) including the high-skilled employment share, ICT investment output ratio, expected output change, as well as a vector of control variables. $\beta_{j}=\left(\beta_{j 1}, \beta_{j 2}, \ldots, \beta_{j k}\right)^{\prime}$ is $(k \times 1)$ vector of parameters and $u_{j t}$ is the error term correspondign to the jth equation. Ordered probit model will estimate, $\alpha_{j 1}, \alpha_{j 2}, \beta_{j}$ plus four unknown thresholds $\mu_{j 1}, \mu_{j 2}, \mu_{j 3}$ and $\mu_{j 4}$. The ordered probit models will be estimated separately for each skill category by using ML. This produces consistent but asymptotically inefficient parameter estimates. The degree of inefficiency depends on the degree of correlation among the error terms. To evaluate the degree of such correlation, one must estimate a seemingly unrelated ordered probit model. In practice, the difference between a single equation ordered probit model and a multivariate ordered probit model, however, is very small (see Breslaw and McIntosh 1998).

\footnotetext{
${ }^{3}$ For a recent application of the determinants of employment expectations see Kaiser (2000).
} 


\subsubsection{Multivariate probit model with endogenous organizational change}

The argument of estimation of a system of equations is stronger if either theory predicts cross-equation restrictions or if an endogenous variable is included on the right-hand side. Since in absence of factor prices symmetry restrictions do not exist, endogeneity of organizational change is more important. The multivariate probit model is a generalization of the bivariate probit model and contains five structural equations: four employment expectation equations and one equation explaining organizational change (subscript $\mathrm{i}$ is suppressed for convenience): ${ }^{4}$

$$
\begin{aligned}
\Delta \widetilde{L}_{j, t+1}^{*} & =\alpha_{1 j} \Delta O C_{t}+\alpha_{j 2} \Delta I C T_{t}+\beta_{j}^{\prime} X_{1 t}+\epsilon_{j t}, j=1,2,3,4 . t=1 \\
\Delta O C_{t}^{*} & =\gamma_{j 1}^{\prime} X_{1 t}+\gamma_{j 2}^{\prime} X_{2 t}+\eta_{t} \\
\Delta \widetilde{L}_{j, t+1} & =1 \text { if } \Delta \widetilde{L}_{j, t+1}^{*}>0 \\
\Delta O C_{t} & =1 \text { if } \Delta O C_{t}^{*}>0 \\
\epsilon_{t}^{\prime} & =\left[\epsilon_{j t}, \eta_{t}\right] \sim N(0, \Sigma)
\end{aligned}
$$

where $\Delta \widetilde{L}_{j, t+1}^{*}$ represents the employment expectations for different types of educational qualifications during the period between 1995 and 1997 (increase=1, 0 otherwise). ${ }^{5} \Delta O C_{t}$ denotes the introduction of organizational change between 1993 and 1995. The vector $X_{2 t}$ contains identifying variables, i.e. variables which are assumed to affect the organizational change but not the employment equations. $\epsilon_{t}^{\prime}$ is assumed to be jointly multivariate normally distributed with zero mean vector. Given that the variance is 1 , the variance-covariance matrix, $\Sigma$, consists of a correlation matrix including 10 free correlation coefficients. The multivariate probit model will be estimated by the simulated MLE (see Greene 1997). In the empirical part of the paper we test whether the error terms between the equation explaining organizational change and each employment expectation are correlated. When the error terms are correlated, excluding the selection equation will not yield consistent estimates of the parameters on organizational change.

\footnotetext{
${ }^{4}$ See Greene (1997) for a description of the multivariate probit model.

${ }^{5}$ Here we simply collapse the first three categories (decrease and stable employment) as well as the increasing categories of the ordered probit model into two categories. The distinction between the decreasing employment category and the stable employment category is not very important for most of the skill categories except for unskilled labour.
} 


\subsection{Hypotheses}

We advance a number of hypotheses concerning the relationship between organizational change, new ICT and how the combination of new ICT and OC affects employment performance.

Hypothesis 1. The impact of organizational change on total employment growth is expected to be negative. For instance, lean administration and flatter hierachies management are often associated with downsizing activities, in particular the reduction of the core workforce.

Hypothesis 2. The impact of organizational change on employment depends on the type of OC.

Hypothesis 3. The effects of organizational change should be positive for highskilled and negative for both medium-skilled and unskilled labor. The reduction of medium-skilled labor can be justified by the fact that OC is often associated with the reduction of middle managers.

Hypothesis 4. ICT-enabled changes in work organizations may be more important than the direct effects of ICT on employment (Bresnahan 1999).

Hypothesis 5. We expect a strong correlation between the introduction of new ICT and the change in the organizational structure. The introduction of ICT, for example, allows for the reduction in the number of hierarchy levels and with the greater access to information that ICT provides, decision-making is more likely to be decentralized.

Hypothesis 6 . The higher the training expenditures in relation to wage costs, the more likely are firms to introduce new organizational practices.

Hypothesis 7. Firms adopting new organizational practices have a relatively high share of skilled labor.

Hypotheses 1 to 3 are about the employment effects of organizational change. According to hypothesis 1 the impact of organizational change on total employment growth is expected to be negative. This can be justified by the fact that lean administration, flatter hierarchies management are often associated with downsizing activities, in particular the reduction of the core workforce. Hypothesis 2 states that the impact of organizational change on employment depends on the type of OC. Hypothesis 3 is about the employment effects of organizational change when employment is disaggregated into different skill levels. The effects of organizational change should be positive for high-skilled and negative for both medium-skilled and unskilled labor. The reduction of medium-skilled labor can 
be justified by the fact that OC is often associated with the reduction of middle managers. The positive effect on highly skilled workers can be justified by the fact that they have a comparative advantage in implementing new technologies due to their ability of solving problems and adapting to changes in the work environment (see Bartel and Lichtenberg 1987). For instance, the introduction of ISO 9000 requires better-motivated employees, fewer mistakes, less rework, less waste and a better use of time and resources and improved communications. According to hypothesis 4, ICT-enabled changes in work organizations may be more important than the direct effects of ICT on employment (Bresnahan 1999). Hypothesis 5 states that the introduction of new ICT and the change in the organizational structure should be strongly correlated. Use of ICT, for example, allows for the reduction in the number of hierarchy levels and thus can facilitate the flattening of the organizational structure. Similarly, with the greater access to information that ICT provides, decision-making is more likely to be decentralized (see Lindbeck and Snower 1996, 2000). The next hypothesis is that the higher the training expenditures in relation to wage costs, the more likely are firms to introduce new organizational practices. This hypothesis is related to Ichniowski, Shaw and Prennushi (1997) who argue that total quality management systems require training to do problem solving and to increase skills for day to day decision-making. Finally, hypothesis 7 states that firms adopting new organizational practices have a relatively high share of skilled labor. This argument is related to the finding of Doms et al. (1997) who found that plants installing high-tech equipment have relatively skilled labor force before and after adoption.

\section{Data and descriptive statistics}

The data set employed for the subsequent empirical analysis contains the first two waves of the Mannheim Service Innovation panel (MIP) 1995 and 1997. The MIP is a stratified random sample, where firms belonging to small industries such as computer and software are slightly over-represented. The aim of the survey is the innovation behavior of service firms.

\subsection{Definition of organizational change and new ICT}

The key variables are the organizational change, new ICT as well as changes in employment, output and wages. The MIP 1995 is the only wave containing information whether new organizational practices have been introduced. Therefore, we 
are unable to use panel data. Our measure of organizational change is a dummy variable which equals 1 for an affirmative response to the question:

'Between 1993 and 1995, has your enterprise significantly changed the organizational structure or introduced new organizational processes/practices?'

Firms who said that they introduced new organizational practices were then asked:

- 'What are the most important types of organizational change?'

Four percent of the firms did refuse answer on the most important type. The questionnaire contains a list with several different types of organizational practices:

- Total quality management systems

- ISO 9000 and following standards ${ }^{6}$

- Lean management, lean selling, flatter hierachies

- Re-engineering

- Decentralization of decision-making, more decentralized structures, increased responsibilities

- use of suppliers and subcontractors, work allocation.

One should note that this list only covers some aspects of organizational change. ICT-enabled organizational changes are not explicitly listed in the example list. It is interesting to note that a large number of firms responded that they introduced new ICT as the most important type of organizational change.

The second key variable is the introduction of new ICT. Firms were asked:

'Between 1993-1995, did your enterprise introduce new production processes or methods to produce to deliver services?'

${ }^{6}$ ISO 9000 is a standard for quality assurance. To obtain the standard, procedures have to be established and then documented. In particular the staff is trained to follow the procedures, the service measured using performance indicators and evaluated against predetermined standards and the firm audited by a recognized external body (see International Standards Organization, ISO). 
Examples include:

- new ICT, in particular software

- Electronic data exchange (EDI) ${ }^{7}$

- Intranet

- Telephone banking.

We use two measures of employment change. The first one is the actual employment growth rate per year between 1994 and 1996, whereas employment is measured as full-time equivalents. In principle it is useful to work with longer time differences (see Roberts and Skoufias 1997). Since attrition is very high, however, we are unable to work with longer time differences. The second measure is employment expectations for different types of labor. In the 1995 questionnaire the respondents were asked about their expectations for total employment, total sales, and different types of educational qualifications during the three year intervals between 1995 and 1997. Five categories for employment expectations can be distinguished: strong increase, slight increase, unchanged, slight decrease, strong decrease. For the ordered probit model we use the untransformed variables. For the system of probit equations employment expectations are regrouped into two categories: expected increase equals ' 1 ', unchanged or decrease equals '0'. Since for both high-skilled and medium-skilled labour only very few firms expect employment to decrease, the distinction between the decreasing employment category and the stable employment category is not very important. Other control variables are sales expectations, the ICT investment wage bill ratio and a complete set of sector and size dummies. In distinguishing between firm size, dummy variables based on the number of full time equivalent workers are used. Five classes of size are considered: $5-9,10-19,20-49,50-249$, and more than 250 employees. Output is defined as sales deflated by the two digit sectoral producer price index. Real wages are defined as average annual wage costs deflated by the sectoral PPI.

\footnotetext{
${ }^{7}$ EDI can be described as a special form of e-mail and is used as a standardized method for organizations to perform routine business transactions electronically.
} 


\subsection{Construction of the estimation sample and item non-response}

The initial sample contains information on 2553 German firms, of which 1629 firms are located in the West and 924 in the East. For the second wave information on 2178 firms is available. Exclusion of firms with less than 5 employees reduces the sample by 141 firms for the first wave and 86 firms for the second wave. Excluding firms with no information on organizational change or the introduction of new ICT into the production process leads to a slight sample reduction by 30 firms. However, for the first wave incomplete information on firms' expectations for different educational qualifications as well as the number of workers by educational qualifications led to a sample reduction by 775 firms to about 1573 firms. Of the 775 observations more than two thirds are discarded due to missing values on the employment expectation variable. A further sample reduction is due to missing information on the remaining variables. We are left with 1556 firms. When the first and the second wave are combined only 1110 firms are left. Missing values for total wages, sales and the dummy variables further reduced the sample to 823 firms.

The sample reduction is quite large, in particular due to missing values on the employment expectations as well as attrition. It is therefore important to know whether firms refusing to answer the employment questions display some systematic pattern depending on both the introduction of ICT and organizational change. For instance, if firms facing negative employment trends avoid to answer the expected employment question rather than report declining employment, and if these firms are less likely to introduce OC, then the coefficient on OC in the employment equation is upward biased. Furthermore, large firms may also be more likely to refuse to answer questions on the number of employees with different skill levels. To check whether a selection bias is introduced, we estimate a probit equation explaining the probability to refuse answer on employment expectations. Right-hand variables are size, sector and innovation dummies and other firm characteristics. ${ }^{8}$ The probit estimates show that there are few systematic factors which increase the probability of item non-response on employment expectations. In particular, the probability of item non-response is similar for firms introducing OC compared to non-adopters. ${ }^{9}$ We find, however, that the probability of item non-response slightly depends on the firm size. We conclude that

\footnotetext{
${ }^{8}$ In principle, the response decision might be explained by the characteristics of the respondents. However, information on individual characteristics of the respondents such as educational qualification as well as occupational status is only available for 70 percent of the firms.

${ }^{9}$ Results are available upon request.
} 
Table 1: Summary statistics: Composition of ICT and organizational change, and other independent variables

\begin{tabular}{|c|c|}
\hline variable & means \\
\hline high-skilled worker share, $L_{H} / L$ & 0.172 \\
\hline ICT investment to wage costs, $I C T / W C$ & 0.052 \\
\hline Training expenditure to wages costs, $T R / W C$ & 0.023 \\
\hline expected output change ( 1 growth, 0 otherwise) & 0.589 \\
\hline dummy east German firm, East & 0.365 \\
\hline types of ICT ( $1=$ yes, 0 otherwise): & \\
\hline new ICT, all types, $\triangle I C T$ & 0.415 \\
\hline introduction of internal or external network, ISDN, $\triangle N E T$ & 0.136 \\
\hline $\mathrm{CAD} / \mathrm{CAE}, \mathrm{SAP}, \triangle C A D$ & 0.027 \\
\hline electronic data exchange, electronic, telebanking, $\Delta E D I$ & 0.044 \\
\hline other new ICT & 0.201 \\
\hline $\begin{array}{l}\text { organizational change in connection with new ICT, } \triangle E R P I C T \\
\text { types of OC ( } 1=\text { yes, } 0 \text { otherwise): }\end{array}$ & 0.187 \\
\hline new organizational practices, all types, $\triangle O C$ & 0.586 \\
\hline organizational change in connection with new ICT, $\triangle E R P I C T$ & 0.187 \\
\hline organizational change due to new ICT, $\triangle O R G I C T$ & 0.067 \\
\hline quality management systems, TQM, ISO900X, $\Delta I S O 900 X$ & 0.107 \\
\hline $\begin{array}{l}\text { lean administration/selling, flatter hierarchies, } \triangle L E A N \\
\text { increased decentralization, responsibility }\end{array}$ & 0.063 \\
\hline or delegation of authority, $\triangle D E C E N T$ & 0.040 \\
\hline fusions, spin-offs, mergers and acquisitions, $\Delta M \& A$ & 0.008 \\
\hline outsourcing, $\triangle O U T$ & 0.012 \\
\hline increased worker training, $\triangle T R A I N$ & 0.007 \\
\hline introd. of profit center, $\triangle P R O F I T$ & 0.012 \\
\hline general change in organizational structure, $\triangle O C G E N$ & 0.118 \\
\hline new workplace characteristics (job rotation, team work), $\triangle W O R K$ & 0.026 \\
\hline increased centralization, $\triangle C E N T R A L$ & 0.026 \\
\hline change in logistics, materials management, $\triangle L O G I S T I C S$ & 0.019 \\
\hline
\end{tabular}

Notes: The number of observations is 1556 . The percentage responded is more than the total of 0.58 and 0.42 for OC and ICT respectively, due to plurality of responses. 
selection bias is not a serious problem. We also check whether the non participating firms in the second wave depend on firm characteristics. We find no evidence that attrition depends on firm characteristics.

\subsection{Descriptive Statistics}

Table 1 and 2 contain information on the key variables based on the 1995 wave. Table 3 shows descriptive statistics for the MIP 1995 combining MIP 1997 wave. Between 1993 and 199559 percent of German Service firms experienced at least one of the types of organizational change identified in the survey (see Table 1). The introduction of quality management programs, such as TQM, quality control and ISO 9000 standards was relatively popular during the three year interval between 1993 and 1995. Approximately 11 percent of the firms introduced such quality management programs or have registered for ISO 9000/9001 standards, followed by lean administration including flatter hierarchies with 6 percent and a delegation of authority or decentralization of decision-making with four percent. 20 percent of the firms reported that the organizational change consists of new ICT, in particular software for planning, order processing, controlling, logistics, materials management as well as electronic order processing, new communication structures, computerized accounting or management system or computer-aided quality assurance or electronic materials management and inventory control for the first time. For about 6 percent of the firms responded that they directly changed the organizational structure due to the introduction of ICT. This indicates that it is difficult to distinguish between employment effects of organizational change and new ICT.

One should note that our measure of $\mathrm{OC}$ is a binary variable rather than the percentage of employees involved in each of the new organizational practices. Therefore descriptive statistics can not be compared with those reported in Osterman (2000). Furthermore, high performance practices such as quality circles, team work, flexible work time are not explicitly listed in the questionnaire. This may explain the fact that only 3 percent of the firms responded that they were introducing HRM practices. Furthermore, the distinction between different types of $\mathrm{OC}$ is not clear-cut. For instance, total quality management systems encompass many of the ideas of employee involvement such as salary promotion, bonus schemes, job rotation, quality circles and functional delegated teams. Therefore, it is difficult to separate both categories.

A large number of firms answered that major new production processes are 
associated with the introduction of new ICT (electronic banking, introduction of network/ISDN, or introduction of new ICT equipment and software) (see Table 1). This table also includes the high-skilled employment share, the ICT investment wage bill ratio and training expenditures in percent of total wage bill. In 1995, the portion of university graduates as a percentage of the total of employees amounts to 17 percent. Approximately 59 percent of the service firms expect sales to increase for the medium-term period 1995 to 1997.

Table 2: Sample distribution of employment expectations (percentage share of total)

\begin{tabular}{lccccc}
\hline & $\begin{array}{c}\text { strong } \\
\text { decrease }\end{array}$ & decrease & stable & increase & $\begin{array}{c}\text { strong } \\
\text { increase }\end{array}$ \\
\hline university graduates, tech. degree $^{a}$ & 0.026 & 0.040 & 0.746 & 0.165 & 0.022 \\
university graduates, other degree & 0.021 & 0.038 & 0.686 & 0.222 & 0.032 \\
masters, technicians & 0.010 & 0.055 & 0.632 & 0.274 & 0.028 \\
vocational degree & 0.015 & 0.110 & 0.504 & 0.308 & 0.063 \\
unskilled and other workers & 0.088 & 0.174 & 0.568 & 0.139 & 0.031 \\
\hline
\end{tabular}

Notes: OBS $=1556 .{ }^{a}$ Including natural science

Source: Mannheim Service Innovation Panel 1995.

Table 2 presents employment expectations. In 1995 between 19 and 25 percent of the firms anticipated an increase in the employment of university graduates depending on the type of degree. The majority of the service firms expected unchanged employment, ranging between 74 percent for university graduates in technical or natural science degrees and 50 percent for workers with a degree from dual vocational system (see Table 2).

Table 3 presents descriptive statistics for the sample combining the first and the second wave. We observe a percentage change in employment of 1.1 percent per year during 1994 and 1996. Real output grew by 5.2 percent and real wages by 3.4 percent. To check the reliability of change in real wage development we also calculate sectoral wages based on national accounts. The difference in real wage growth across both data sources, however, is very small.

Table 4 presents the average employment growth rate per year for firms introducing organizational changes or new ICT. As expected, firms with organizational changes or new ICT have higher employment growth rates than non-adopters. While firms introducing new organizational practices show a percentage change 
Table 3: Summary statistics

\begin{tabular}{lccccr}
\hline & mean & median & std dev & min. & max. \\
\hline \% change in employment, $\Delta \ln L$ & .011 & .000 & .170 & -.865 & 1.469 \\
$\%$ change in output, $\Delta \ln Y$ & .055 & .028 & .265 & -.821 & 2.903 \\
\% change in real output, $\Delta \ln (Y / P)$ & .052 & .026 & .257 & -.836 & 2.259 \\
$\%$ change in wages $\Delta \ln W$ & .037 & .037 & .103 & -.438 & 0.477 \\
$\%$ change in real wages, $\Delta \ln (W / P)$ & .034 & .032 & .107 & -.453 & 0.462 \\
\%. in real sector wages, $\Delta \ln \left(W^{\mathrm{sec}} / P\right)$ & .038 & .050 & .038 & -.065 & 0.084 \\
$\%$ change in output prices, $\Delta \ln P$ & .003 & .010 & .025 & -.049 & 0.050 \\
high-skilled workers share, $L_{H} / L$ & .184 & .077 & .238 & 0 & 1 \\
training expend. to wage costs, $T R / W C$ & .023 & .010 & .034 & 0 & 0.286 \\
ICT investment to wage costs, $I C T / W C$ & .061 & .025 & .061 & 0 & 1 \\
new ICT (1=yes, 0 otherw.), $\Delta I C T$ & .416 & & & 0 & 1 \\
organizational change, $\Delta O C$ & .550 & & & 0 & 1 \\
dummy east German firm, $\Delta E A S T$ & .377 & & & 0 & 1 \\
\hline
\end{tabular}

Notes: The sample consists of 823 observations during the years 1994 and 1996. L denotes employees (full time equivalents) Y denotes total sales or total income, $\mathrm{W}$ total wage costs per employee, $\mathrm{P}$ denotes the price index of the gross value of output, $\mathrm{W}^{S E C}$ denotes sectoral total wages costs per employee (two digit level), $L_{H} / L$ denotes the share of workers with a university degree, TR/WC denotes training expenditures in percent of total wage bill. ICT/WC denotes the ratio of training expenditures to total wage bill. Growth rates are measured as average annual percentage change.

Source: Mannheim Service Innovation Panel 1995 and 1997, own calculations.

in employment of 2.8 , the corresponding growth rate for non-adopters is -1.0 percent.

Table 5 presents simple cross tabulations between employment expectations of different skill types and organizational change. The percentage of firms with an employment change for one of the five skill levels is compared between adopters and non-adopters of organizational change. We see in Table 5 that the percentage of firms with increasing employment is higher in firms introducing new organizational practices. The difference between adopters and non-adopters ranges between 5 percentage points for medium-skilled labor and 17 percentage points for university graduates with a non-technical degree or natural science degree. This table also includes statistical tests examining the relationship between the employment expectations of different skill levels and whether or not firms introduce organizational change. Kendall's tau-b is a non-parametric measure of associa- 
Table 4: Actual employment change for adopters and non-adopters $\Delta \mathrm{OC}=0 \quad \Delta \mathrm{OC}=1 \quad \Delta \mathrm{ICT}=0 \quad \Delta \mathrm{ICT}=1$ percentage change in

employment per year $\quad \begin{array}{llll}-0.010 & 0.028 & 0.005 & 0.020\end{array}$

Source: Mannheim Service Innovation Panel 1995 and 1997, own calculations.

Table 5: Employment expectations for adopters and non-adopters of OC employment expectations between 1995-1997 workers with a university degree masters/ technical fields other fields technicians

\begin{tabular}{|c|c|c|c|c|c|c|}
\hline & $\Delta \mathrm{OC}=0$ & $\Delta \mathrm{OC}=1$ & $\Delta \mathrm{OC}=0$ & $\Delta \mathrm{OC}=1$ & $\Delta \mathrm{OC}=0$ & $\Delta \mathrm{OC}=1$ \\
\hline strong decrease & 0.034 & 0.020 & 0.030 & 0.015 & 0.016 & 0.007 \\
\hline decrease & 0.043 & 0.038 & 0.040 & 0.036 & 0.053 & 0.057 \\
\hline stable & 0.801 & 0.707 & 0.775 & 0.624 & 0.689 & 0.591 \\
\hline increase & 0.113 & 0.202 & 0.141 & 0.280 & 0.228 & 0.307 \\
\hline strong increase & 0.008 & 0.033 & 0.014 & 0.045 & 0.014 & 0.038 \\
\hline Kendall's tau-b & \multicolumn{2}{|c|}{0.135} & \multicolumn{2}{|c|}{0.176} & \multicolumn{2}{|c|}{0.103} \\
\hline Fisher's exact test, $\rho$ & \multicolumn{2}{|c|}{0.000} & \multicolumn{2}{|c|}{0.000} & \multicolumn{2}{|c|}{0.000} \\
\hline & \multicolumn{2}{|c|}{ vocational degree } & \multicolumn{2}{|c|}{ unskilled workers } & & \\
\hline & $\Delta \mathrm{OC}=0$ & $\Delta \mathrm{OC}=1$ & $\Delta \mathrm{OC}=0$ & $\Delta \mathrm{OC}=1$ & & \\
\hline strong decrease & 0.012 & 0.016 & 0.064 & 0.105 & & \\
\hline decrease & 0.099 & 0.117 & 0.138 & 0.198 & & \\
\hline stable & 0.553 & 0.470 & 0.629 & 0.525 & & \\
\hline decrease & 0.287 & 0.322 & 0.144 & 0.136 & & \\
\hline strong increase & 0.048 & 0.073 & 0.025 & 0.035 & & \\
\hline Kendall's tau-b & \multicolumn{2}{|c|}{0.039} & \multicolumn{2}{|c|}{-0.067} & & \\
\hline Fisher's exact test, $\rho$ & \multicolumn{2}{|c|}{0.000} & \multicolumn{2}{|c|}{0.000} & & \\
\hline
\end{tabular}

Notes: The two-sided Fisher's exact test determine if there are non-random associations between two variables, where both variables can be ordinal. $\rho$ denotes the marginal significance level. Kendall's tau-b is a non-parametric measure of association based on the number of concordances and discordances in paired observations; its value ranges from -1.0 (no association) to 1.0 (perfect association).

Source: Mannheim Service Innovation Panel 1995, own calculations. 
Table 6: Employment expectations for adopters and non-adopters of ICT

Employment expectations between 1995-1997

\begin{tabular}{|c|c|c|c|c|c|c|}
\hline & \\
\hline & \multicolumn{4}{|c|}{ workers with a university degree } & \multicolumn{2}{|c|}{$\begin{array}{c}\text { masters/ } \\
\text { technnicians }\end{array}$} \\
\hline & $\Delta \mathrm{OC}=0$ & $\Delta \mathrm{OC}=1$ & $\Delta \mathrm{OC}=0$ & $\Delta \mathrm{OC}=1$ & $\Delta \mathrm{OC}=0$ & $\Delta \mathrm{OC}=1$ \\
\hline strong decrease & 0.030 & 0.020 & 0.026 & 0.014 & 0.016 & 0.002 \\
\hline decrease & 0.036 & 0.046 & 0.038 & 0.037 & 0.051 & 0.062 \\
\hline stable & 0.777 & 0.703 & 0.741 & 0.610 & 0.665 & 0.585 \\
\hline increase & 0.133 & 0.211 & 0.165 & 0.303 & 0.245 & 0.332 \\
\hline strong increase & 0.024 & 0.020 & 0.030 & 0.036 & 0.023 & 0.036 \\
\hline Kendall's tau-b & \multicolumn{2}{|c|}{0.072} & \multicolumn{2}{|c|}{0.145} & \multicolumn{2}{|c|}{0.080} \\
\hline Fisher's exact test, $\rho$ & \multicolumn{2}{|c|}{0.001} & \multicolumn{2}{|c|}{0.000} & \multicolumn{2}{|c|}{0.000} \\
\hline & \multicolumn{2}{|c|}{ vocational degree } & \multicolumn{2}{|c|}{ unskilled workers } & & \\
\hline & $\Delta \mathrm{OC}=0$ & $\Delta \mathrm{OC}=1$ & $\Delta \mathrm{OC}=0$ & $\Delta \mathrm{OC}=1$ & & \\
\hline strong decrease & 0.014 & 0.015 & 0.077 & 0.104 & & \\
\hline decrease & 0.109 & 0.111 & 0.155 & 0.200 & & \\
\hline stable & 0.507 & 0.502 & 0.576 & 0.557 & & \\
\hline decrease & 0.308 & 0.308 & 0.163 & 0.107 & & \\
\hline strong increase & 0.063 & 0.063 & 0.030 & 0.033 & & \\
\hline Kendall's tau-b & \multicolumn{2}{|c|}{-0.001} & \multicolumn{2}{|c|}{-0.086} & & \\
\hline Fisher's exact test, $\rho$ & \multicolumn{2}{|c|}{0.998} & \multicolumn{2}{|c|}{0.003} & & \\
\hline
\end{tabular}

Notes: See Table 5.

Source: Mannheim Service Innovation Panel 1995, own calculations.

tion with values ranging between -1.0 (no association) to 1.0 (perfect association). Furthermore, the two-sided Fisher's exact test can be calculated to determine if there are non-random associations between organizational change and employment expectations for different skill types. This test is also appropriate if one of the variable is ordinal. We see that the relationship between employment expectations by skill level and OC is significantly positive except for unskilled workers. In this case the correlation coefficient is significantly negative (see Table 5).

Table 6 presents simple cross tabulations between employment expectations of different skill types and new ICT. As expected, employment expectations for unskilled labor are negatively related to new ICT. For university graduates as well as masters and technicians we find a significantly positive correlation between employment expectations and new ICT. In contrast, the correlation coefficient 
between employment expectations for workers with a vocational degree is close to zero and not significantly different from zero.

\section{Empirical results}

\subsection{Impact of OC on actual employment growth}

We begin by reporting the labor demand estimates using the annual average percentage change in total employment between 1994 and 1996 as the dependent variable. We estimated the two equations system of equations 2.2 and 2.3 by maximum likelihood and compared it to the OLS estimate of equation 2.1. Table 7 gives the regression results. Since the t-test as well as the LR-test cannot reject the null hypothesis of zero correlation between the error term of the probit equation and the labor demand equation, the interpretation only focuses on the OLS results. Surprisingly we find that the impact of the introduction of new organizational practices or new organizational structures is positive with a coefficient of about 0.03 and significant at the 5 percent level. This means that adopters of new organizational practices grow 3 percentage points faster than non-adopters given the impact of wages, output and other firm characteristics. While the wage elasticity is quite reasonable with about -0.36 , the output elasticity is only 0.25 . The relatively low output elasticity may be related to the use of the short time difference estimator with only two years. Roberts and Skoufias (1997) suggested that shorter time differences lead to a download bias of the output elasticities. However, we are unable to use longer time differences. When using four time differences combing 1994 and 1998 data the sample size decreases to about 400 firms.

Another key finding is the close link between the use of ICT and organizational change supporting hypothesis 4 . Table 7 , column 3 shows that firms introducing new ICT in the three year period between 1993 and 1995 were much more likely to experience new organizational practices in this period. Furthermore, the positive coefficient on ICT investment as percentage of total wage bill indicates that ICTintensive firms are more likely to introduce organizational changes.

It is likely that the employment effects vary across the different types of new organizational practices. In order to explore this idea, we reestimate the labor demand function using various interaction terms. In particular organizational change can be interacted with the most common types of OC: new ICT used for organizational practices, $\triangle E R P I C T$, organizational change due to new ICT, 
Table 7: Determinants of actual employment growth

\begin{tabular}{|c|c|c|c|}
\hline & \multirow{2}{*}{$\begin{array}{c}\text { OLS } \\
\Delta \ln L\end{array}$} & \multicolumn{2}{|c|}{$\begin{array}{l}\text { Treatment effects } \\
\text { model, ML }\end{array}$} \\
\hline & & $\Delta \ln L$ & $\triangle O C^{*}$ \\
\hline$\Delta \ln (Y / P)$ & $\begin{array}{c}0.252 \\
(4.18)\end{array}$ & $\begin{array}{l}0.252 \\
(4.23)\end{array}$ & \\
\hline$\Delta \ln (W / P)$ & $\begin{array}{l}-0.359 \\
(-5.63)\end{array}$ & $\begin{array}{l}-0.359 \\
(-5.70)\end{array}$ & \\
\hline$\triangle O C$ & $\begin{array}{c}0.030 \\
(2.24)\end{array}$ & $\begin{array}{c}0.008 \\
(0.37)\end{array}$ & \\
\hline$\triangle I C T$ & $\begin{array}{c}-0.008 \\
(-0.66)\end{array}$ & & $\begin{array}{l}1.307 \\
(12.25)\end{array}$ \\
\hline$L^{H} / L$ & $\begin{array}{l}0.063 \\
(2.30)\end{array}$ & $\begin{array}{l}0.064 \\
(2.36)\end{array}$ & $\begin{array}{l}0.114 \\
(0.40)\end{array}$ \\
\hline$I C T / W C$ & $\begin{array}{c}-0.014 \\
(-0.45)\end{array}$ & & $\begin{array}{l}1.015 \\
(2.24)\end{array}$ \\
\hline$T R / W C$ & $\begin{array}{c}-0.057 \\
(-0.37)\end{array}$ & & $\begin{array}{l}8.025 \\
(3.27)\end{array}$ \\
\hline$E A S T$ & $\begin{array}{c}0.011 \\
(1.01)\end{array}$ & $\begin{array}{c}0.011 \\
(1.06)\end{array}$ & $\begin{array}{l}0.074 \\
(0.68)\end{array}$ \\
\hline size10 - 19 & $\begin{array}{l}0.003 \\
(0.17)\end{array}$ & $\begin{array}{l}0.004 \\
(0.22)\end{array}$ & $\begin{array}{l}0.055 \\
(0.32)\end{array}$ \\
\hline size $20-49$ & $\begin{array}{c}-0.013 \\
(-0.78)\end{array}$ & $\begin{array}{c}-0.010 \\
(-0.57)\end{array}$ & $\begin{array}{l}0.446 \\
(2.70)\end{array}$ \\
\hline size $50-249$ & $\underset{(-0.74)}{-0.012}$ & $\begin{array}{c}-0.008 \\
(-0.49)\end{array}$ & $\begin{array}{l}0.580 \\
(3.58)\end{array}$ \\
\hline size $>=250$ & $\begin{array}{c}-0.022 \\
(-1.04)\end{array}$ & $\begin{array}{c}-0.014 \\
(-0.59)\end{array}$ & $\frac{1.228}{(6.21)}$ \\
\hline industry dummies & yes & yes & yes \\
\hline constant & $\begin{array}{c}-0.011 \\
(-0.48)\end{array}$ & $\begin{array}{l}0.008 \\
(-0.34)\end{array}$ & $\begin{array}{l}-1.042 \\
(-5.04)\end{array}$ \\
\hline correl. coeff, $\rho ; \mathrm{LR}-\mathrm{T}$. & & $\begin{array}{r}0.091 \\
(0.86)\end{array}$ & 0.85 \\
\hline F-test/LR test ind. D. & $2.4^{*}$ & $21.1^{* *}$ & $11.0^{* *}$ \\
\hline F-test/LR test size & 0.6 & 1.0 & $54.9^{* *}$ \\
\hline obs & 823 & 823 & 823 \\
\hline Adj. $R^{2}$ & 0.205 & & \\
\hline
\end{tabular}

Notes: The dependent variable is the average annual percentage change of employment during the period 1994 and 1996. t-values, given in parentheses, are based on robust standard errors. 
$\triangle O R G I C T$, lean administration/selling, flatter hierarchies, $\triangle L E A N$ and decentralization of the organizational structure. Table 8 documents that there are no significant differences across different new organizational practices. In particular, we find that the coefficient on administration/selling, flatter hierarchies has the expected negative sign but is not significant at the 10 percent level ( $t$-value $=1.5)$.

We next estimate an equation describing the 25 th and 75 th quantile. The 0.75 quantile of annual percentage change in employment per year is about 0.062 and the 0.25 quantile is -0.059 . The results are given in the second and third column of Table 8. In comparison with previous OLS results, the coefficient on $\Delta$ OC turns to be insignificant in shrinking firms, while it remains significant in the other part of the distribution. We also find that the output elasticity is significantly higher in firms with fast employment growth than in shrinking firms. Similarly, the responsiveness of wages to employment is higher in firms with fast employment growth.

\subsection{Impact of OC on employment expectations}

\subsubsection{Ordered probit results}

In the next step of our investigations we examine the relationship between the introduction of new organizational practices and the firms' employment plans. Table 9 presents the results for the ordered probit model. This table includes the coefficients on the probability of expected employment change for five skill groups between 1995 and 1997. The underlying dependent variable is ordered categorical distributed between 0 (planned strong decrease) and 4 (planned strong increase). We find that the introduction of $\mathrm{OC}$ has a positive impact on expected employment for all skill levels except for unskilled labor. Looking at the interaction dummies with different types of organizational change, introducing decentralized organizational structure tends to decrease both the number of workers with a vocational certificate from the dual vocational system and unskilled workers. The introduction of the ISO 9000 standard tends to increase the employment of university graduates with a degree in engineering or natural science. All other coefficients have the predicted signs. Expected employment growth for different types of labor is rather responsive to expected output growth. Emploment expectations for high-skilled labor are also significantly positive related to the skill intensity of the firm measured as the university graduates employment share.

To illustrate the quantitative effect of organizational change we calculate the predictions of the ordered probit model compared for adopters of OC and non- 
Table 8: Employment effects of different types of OC and quantile regressions

\begin{tabular}{|c|c|c|c|}
\hline & \multirow{2}{*}{$\begin{array}{c}\text { OLS } \\
\text { interaction } \\
\text { terms }\end{array}$} & \multicolumn{2}{|c|}{$\begin{array}{c}\text { Quantile } \\
\text { regression }\end{array}$} \\
\hline & & Q25 & Q75 \\
\hline$\Delta \ln (Y / P)$ & $\begin{array}{l}0.255 \\
(4.23)\end{array}$ & $\begin{array}{l}0.197 \\
(3.15)\end{array}$ & $\begin{array}{c}0.417 \\
(5.66)\end{array}$ \\
\hline$\Delta \ln (W / P)$ & $\begin{array}{c}-0.364 \\
(-5.70)\end{array}$ & $\underset{(-6.32)}{-0.351}$ & $\begin{array}{c}-0.456 \\
(-5.47)\end{array}$ \\
\hline$\triangle O C$ & $\begin{array}{c}0.037 \\
(2.71)\end{array}$ & $\begin{array}{c}0.003 \\
(0.24)\end{array}$ & $\begin{array}{c}0.028 \\
(2.43)\end{array}$ \\
\hline$\triangle E R P I C T$ & $\begin{array}{c}-0.016 \\
(-1.09)\end{array}$ & & \\
\hline$\triangle I C T O R G A$ & $\begin{array}{l}0.011 \\
(0.47)\end{array}$ & & \\
\hline$\triangle T Q M$ & $\begin{array}{c}0.011 \\
(0.41)\end{array}$ & & \\
\hline$\triangle L E A N$ & $\begin{array}{c}-0.033 \\
(-1.48)\end{array}$ & & \\
\hline$\triangle D E C E N T$ & $\begin{array}{l}-0.045 \\
(-1.59)\end{array}$ & & \\
\hline$\triangle I C T$ & $\begin{array}{c}-0.005 \\
(0.38)\end{array}$ & $\begin{array}{c}-0.007 \\
(-0.60)\end{array}$ & $\begin{array}{c}-0.011 \\
(-0.83)\end{array}$ \\
\hline$L^{H} / L$ & $\begin{array}{c}0.063 \\
(2.31)\end{array}$ & $\begin{array}{c}0.009 \\
(0.30)\end{array}$ & $\begin{array}{l}0.072 \\
(2.36)\end{array}$ \\
\hline$E A S T$ & $\begin{array}{c}0.010 \\
(0.92)\end{array}$ & $\begin{array}{c}0.012 \\
(1.15)\end{array}$ & $\begin{array}{c}-0.005 \\
(-0.49)\end{array}$ \\
\hline size, sec. dummies & yes & yes & yes \\
\hline constant & $\frac{-0.011}{(-0.55)}$ & $\underset{(-1.86)}{-0.034}$ & $\underset{(2.20)}{0.042}$ \\
\hline Adj./Pseudo $R^{2}$ & 0.207 & 0.107 & 0.197 \\
\hline obs & 823 & 823 & 823 \\
\hline
\end{tabular}

Notes: The dependent variable is the average annual percentage change in employment during the period 1994 and 1996. t-values based on robust standard errors are given in parentheses. t-values of the simultaneous quantile regression are based on Bootstrap standard errors with 200 replications. 
Table 9: Ordered probit estimates for firms' employment expectations

\begin{tabular}{|c|c|c|c|c|c|}
\hline & $\begin{array}{c}\text { university } \\
\text { graduates } \\
\text { tech., n.s. } \\
\text { degree }\end{array}$ & $\begin{array}{c}\text { university } \\
\text { graduates } \\
\text { other } \\
\text { degree }\end{array}$ & $\begin{array}{c}\text { masters } \\
\text { technicians }\end{array}$ & $\begin{array}{c}\text { vocational } \\
\text { degree }\end{array}$ & $\begin{array}{c}\text { unskilled, } \\
\text { and other } \\
\text { workers }\end{array}$ \\
\hline$\triangle O C$ & $\begin{array}{l}0.14 \\
(1.76)\end{array}$ & $\begin{array}{l}0.17 \\
(2.35)\end{array}$ & $\begin{array}{l}0.19 \\
(2.56)\end{array}$ & $\begin{array}{l}0.21 \\
(2.94)\end{array}$ & $\begin{array}{c}0.00 \\
(-0.06)\end{array}$ \\
\hline$\triangle O R G I C T$ & & & $\begin{array}{l}-0.38 \\
(-3.15)\end{array}$ & $\begin{array}{l}-0.33 \\
(-2.99)\end{array}$ & $\begin{array}{l}0.21 \\
(1.94)\end{array}$ \\
\hline$\triangle I S O 900 X$ & $\begin{array}{l}0.34 \\
(2.89)\end{array}$ & & & & \\
\hline$\triangle L E A N$ & & & & $\begin{array}{c}-0.22 \\
(-1.72)\end{array}$ & \\
\hline$\triangle D E C E N T$ & & & & $\begin{array}{c}-0.47 \\
(-3.20)\end{array}$ & $\begin{array}{l}-0.32 \\
(-2.21)\end{array}$ \\
\hline$\triangle I C T$ & $\begin{array}{l}0.01 \\
(0.07)\end{array}$ & $\begin{array}{l}0.14 \\
(2.01)\end{array}$ & $\begin{array}{l}0.17 \\
(2.38)\end{array}$ & $\begin{array}{l}0.00 \\
(0.06)\end{array}$ & $\begin{array}{l}-0.13 \\
(-1.91)\end{array}$ \\
\hline$\triangle E X P Y$ & $\begin{array}{l}0.24 \\
(3.46)\end{array}$ & $\begin{array}{l}0.24 \\
(3.72)\end{array}$ & $\begin{array}{l}0.21 \\
(3.31)\end{array}$ & $\begin{array}{l}0.39 \\
(6.57)\end{array}$ & $\begin{array}{l}0.30 \\
(5.07)\end{array}$ \\
\hline$L^{H} / L$ & $\begin{array}{l}0.95 \\
(4.46)\end{array}$ & $\begin{array}{l}0.60 \\
(3.14)\end{array}$ & $\begin{array}{c}-0.69 \\
(-3.90)\end{array}$ & $\frac{-0.71}{(-4.55)}$ & $\begin{array}{l}-0.25 \\
(-1.53)\end{array}$ \\
\hline$E A S T$ & $\begin{array}{l}-0.08 \\
(-1.13)\end{array}$ & $\begin{array}{l}-0.22 \\
(-3.29)\end{array}$ & $\begin{array}{l}-0.24 \\
(-3.80)\end{array}$ & $\begin{array}{l}0.01 \\
(0.22)\end{array}$ & $\begin{array}{l}0.10 \\
(1.70)\end{array}$ \\
\hline industry, size & yes & yes & yes & yes & yes \\
\hline Pseudo $\mathrm{R}^{2}$ & 0.077 & 0.077 & 0.035 & 0.040 & 0.045 \\
\hline
\end{tabular}

Notes: T-values in parentheses. Number of Observations is 1556. The dependent variable is the probability of employment change (five categories). 
Table 10: Predicted probabilities for innovator and non-innovators

\begin{tabular}{llccccc}
\hline & & $\begin{array}{c}\text { strong } \\
\text { decrease }\end{array}$ & decrease & stable & increase & $\begin{array}{c}\text { strong } \\
\text { increase }\end{array}$ \\
\hline tech, natural sc. & $\Delta \mathrm{OC}=0$ & 0.045 & 0.056 & 0.768 & 0.121 & 0.010 \\
university degree & $\Delta \mathrm{OC}=1$ & 0.021 & 0.032 & 0.722 & 0.197 & 0.027 \\
other university & $\Delta \mathrm{OC}=0$ & 0.040 & 0.058 & 0.735 & 0.152 & 0.014 \\
degree & $\Delta \mathrm{OC}=1$ & 0.014 & 0.027 & 0.654 & 0.263 & 0.042 \\
masters, & $\Delta \mathrm{OC}=0$ & 0.016 & 0.072 & 0.663 & 0.230 & 0.019 \\
technicians & $\Delta \mathrm{OC}=1$ & 0.008 & 0.046 & 0.609 & 0.303 & 0.034 \\
vocational & $\Delta \mathrm{OC}=0$ & 0.017 & 0.116 & 0.518 & 0.294 & 0.055 \\
degree & $\Delta \mathrm{OC}=1$ & 0.014 & 0.103 & 0.498 & 0.316 & 0.068 \\
unskilled, & $\Delta \mathrm{OC}=0$ & 0.071 & 0.155 & 0.581 & 0.156 & 0.036 \\
other workers & $\Delta \mathrm{OC}=1$ & 0.098 & 0.181 & 0.565 & 0.128 & 0.027 \\
\hline
\end{tabular}

Notes: Predictions of the ordered probit model are compared for adopters of OC $(\Delta \mathrm{OC}=1)$ and non adopters $(\Delta \mathrm{OC}=0)$. Number of observations is 1556 .

adopters (see Table 10). The difference between adopters and non-adopters is quite remarkable. Whereas 23 percent of firms introducing major organizational changes in the past expect an increase in the employment of university graduates in technical fields or natural science, the corresponding figure for non-adopters is 13 percent. For university graduates in other fields the difference in expected employment increase between adopters and non-adopters is quite more impressive with about 13 percentage points. For the two medium-skilled groups, the difference in expected employment increase between adopters and non-adopters ranges between 9 percentage points for masters and technicians and 3 percentage points for workers with a certificate from the dual vocational system. In case of unskilled labor employment prospects of non-adopters of OC are better than for adopters. The difference between both groups ranges between 5 percent in the category decreasing employment and 4 percent in the group increasing employment.

\subsubsection{Results from the multivariate probit model}

To account for endogeneity of organizational change in the labor demand equations a selection equation explaining organizational change is added to the system of equations. The ordered categorical variables of the employment expectations 
are regrouped in a binary variable, where 1 equals an increase and 0 stable or unchanged employment. For all specifications we use 200 replications for the Geweke-Hajivassilou-Keane (GHK) estimator. Different values for the number of replications indicate that the likelihood values have already stabilized using 100 replications. The coefficients on 9 industry dummies as well as four size dummies are not reported due to space limitations, but they are jointly significant at the 5 percent level.

Table 11 shows the results for the baseline multivariate probit model which contains four different equations of employment expectation and one equation for new organizational practices. ${ }^{10}$ This table also includes the estimated correlation matrix for the five equations. The correlation coefficients of the error terms are significant at the 5 percent level in six out of ten cases. The positive correlation coefficients of errors terms between the different labor demand equations indicate that firms expecting an increase for one employment group are also expecting an increase for the other employment group conditional on the right-hand variables. In general, the correlations are quite reasonable, with the highest correlation between masters and technicians and workers with university degree. Two out of four correlation coefficients between the errors in the employment equations and the organizational change equation are significant at the five percent level. This indicates that organizational change is not exogenous in the labor demand equation. In addition to the t-test, a Wald test is carried out for the null hypothesis $\mathrm{H}_{0}: \rho_{n 5}=0, \mathrm{n}=1, . .4$, against $\mathrm{H}_{1}: \rho_{n 5} \neq 0, \mathrm{n}=1, . .4$. For the baseline specification the chi-squared test statistic is 12.1 and therefore larger than the 5 percent critical value with 4 degrees of freedom.

Table 11 column 1-4 shows the coefficients on the probability that firms expect an increase in university graduates, master/technicians, workers with a vocational degree and unskilled labor, respectively. Column 5 shows the coefficients on the probability that firms introduce new organizational practices between 1993 and 1995. The most important result is that the employment effects of OC are robust to potential endogeneity of OC. Again there is a significantly positive correlation between $\triangle \mathrm{OC}$ and either high-skilled labor or masters and technicians. For workers with a certificate from the dual vocational system the coefficient is positive but only significant at the 10 percent level.

Turning to the determinants of organizational change the significantly positive coefficient on training expenditures in percent of total wage costs indicates

\footnotetext{
${ }^{10}$ Since the multivariate probit model consisting of six equations did not converge, I combine the two highest skill groups into one category.
} 
Table 11: Simulated MLE of the multivariate probit model for firms' employment expectations and determinants of organizational change

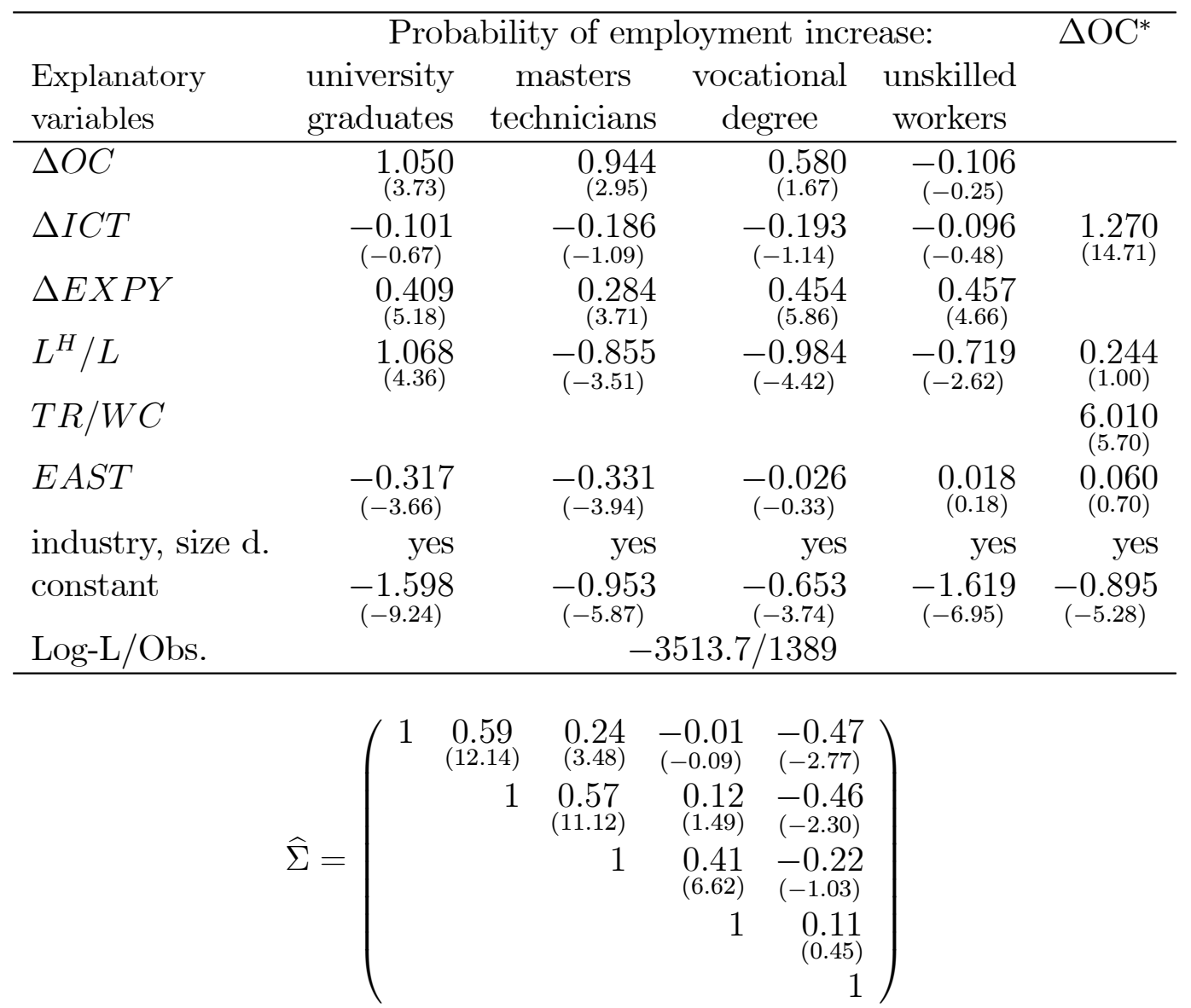

Notes. GHK estimator with 200 replications, t-values are in parantheses. 
that the probability to introduce new organizational practices depends on ratio of the training expenditures to total wage costs. Furthermore, the high skilled employment share is positive but not significant at the 5 percent level. Caroli et al. (2000), however, found a significantly positive relationship between human capital and the propensity to introduce new organizational structures.

For comparison, the multivariate probit estimates assuming exogeneity of organizational change are provided in Table 12. Even though the sign and significance level of the coefficient on organizational change are quite similar across the models, the magnitude of the organizational change effect is remarkably larger based on the multivariate model with endogenous organizational change.

\section{Conclusions}

The paper deals with the impact of both organizational changes and the introduction of new ICT on the firms' expectations for future employment as well as actual employment growth. Special attention is directed to potential endogeneity of OC using treatment effect models as well as multivariate probit models estimated using simulated ML methods. We find the past introduction of new organizational practices or changes in the organizational structure have a significantly positive effect on actual employment growth given output and factor price changes. The employment effect is robust to the potential endogeneity of organizational change in the labor demand equation. The employment effect of OC, however, is higher for firms who have higher than the 0.75 quantile employment growth rates than for firms who are in other parts of the distribution ( 0.25 quantile). Furthermore, we find that organizational change has a significant and positive impact on expected employment for all skill groups except for unskilled labor. Controlling for endogeneity of OC in the labor demand equations resulted in a larger OC effect on employment expectations. The results on the employment effects of ICT are not clear-cut. We find some evidence that the indirect effect of ICT via organizational change, i.e. ICT-enabled changes in work organizations are more important than the direct effects of ICT on employment. Estimation results for the equation explaining organizational change indicate that the introduction of new ICT and training expenditures are primary forces behind organizational change. 
Table 12: Simulated MLE of the multivariate probit model for firms' employment expectations

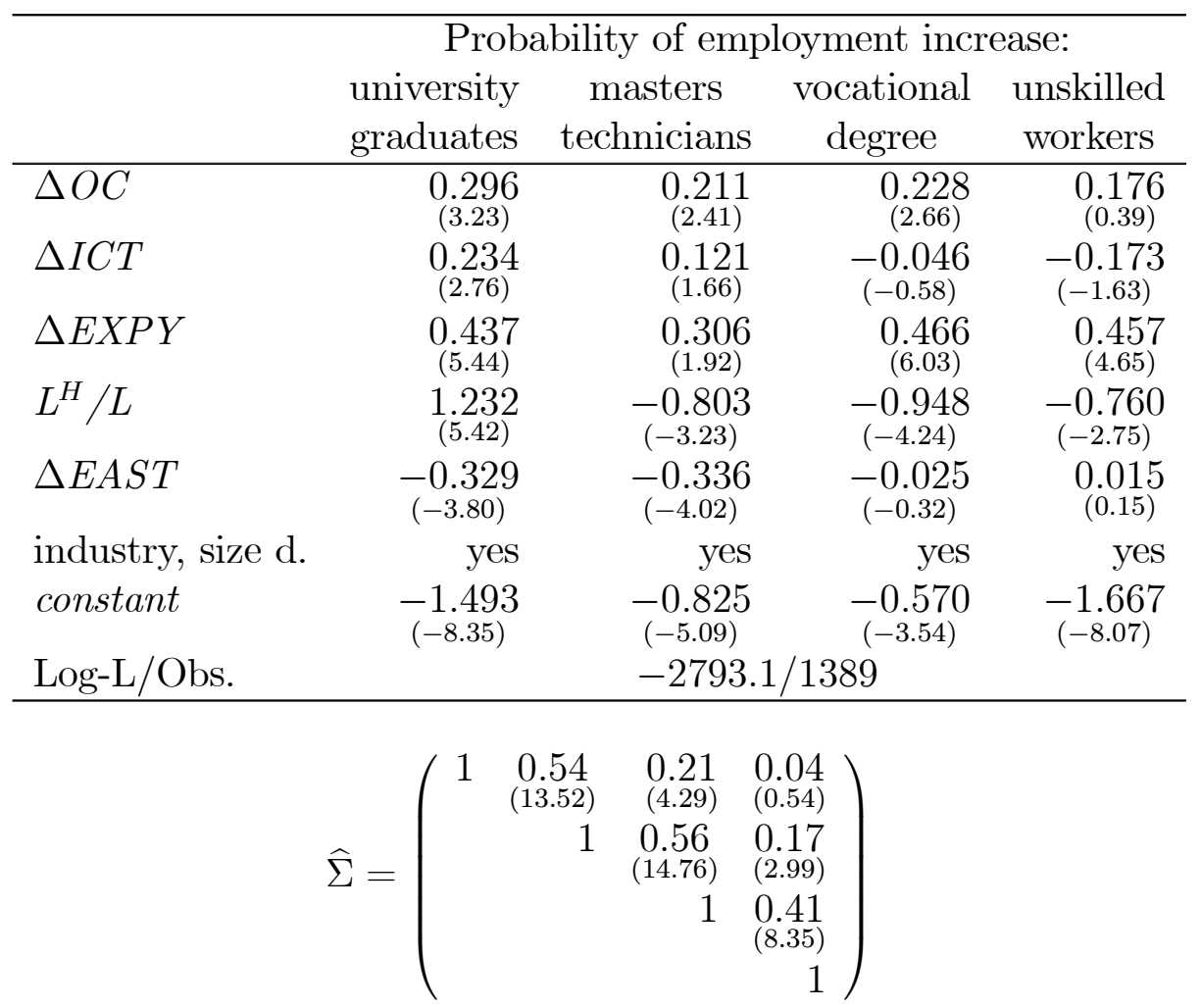

Notes. GHK estimator with 200 replications, t-values are in parantheses. 


\section{References}

[1] Barnow, B. G. Cain and A. Goldberger, 1981. 'Issues in the analysis of selection bias', Evaluation studies, 5, E. W Stromsdorfer and G. Farkus (eds).

[2] Bartel, A. and F. R. Lichtenberg, 1987, 'The Comparative Advantage of Educated Workers in Implementing New Technology', Review of Economics and Statistics, 69, 1, 1-11.

[3] Batt, R, 1999, 'Work Organization, Technology, and Performance in Customer Service and Sales', Industrial and Labor Relations Review, 52,4, 539564 .

[4] Bauer, T. and S. Bender, 2000, 'Organizational Change and Wages: Evidence from Matched Employer-Employee data, paper presented at the IZA confercence 'Organizational Change and its Implications for the Labor Market', November 26-27, 2000.

[5] Breslaw, J. and J. McIntosh, 1998, 'Simulated Latent Variable Estimation of Models with Ordered Categorical Data', Journal of Econometrics, 87, 25-47.

[6] Bresnahan, T., 1999, 'Computerization and Wage Dispersion: An Analytical Reinterpretation', Economic Journal 109, 456, 390-415.

[7] Bresnahan, T., E. Brynjolfsson and L. Hitt, 2001, 'Information Technology, Workplace Organization and the Demand for Skilled Labor: Firm-level Evidence', forthcoming in: Quarterly Journal of Economics.

[8] Brynjolfsson, E and L. M. Hitt, 1998, Information Technology and Organizational design: Evidence from Micro data. mimeo.

[9] Caroli, E and J. Van Reenen, 2001, 'Skill-biased Organizational Change? Evidence from a panel of British and French establishments', forthcoming in: Quarterly Journal of Economics.

[10] Caroli, E., N. Greenan and D. Guellec, 2001, 'Organizational change and skill accumulation', forthcoming in: Industrial and Corporate change.

[11] Chennells, L. and J. Van Reenen, 1999, 'Technical Change and the Structure of Employment of Wages: A Survey of the Micro-Econometric Evidence', Institute for Fiscal Studies, London. 
[12] Doms, M., T. Dunne and K. R. Troske, 1997, Workers, Wages, and Technology', Quarterly Journal of Economics, 112, 1, 253-290.

[13] Egger, H. and V. Grossmann, 2000, 'Empowerment, Reorganization of Work, and Wage Inequality. Paper presented at the IZA workshop 'Organizational change and its implications for the Labor market', 27/28.11.2000 in Bonn.

[14] Greene, W., 1997, Econometric Analysis, Prentice-Hall, NJ.

[15] Ichniowski, C., K. Shaw, G. Prennushi, 1997, 'The Effects of Human Resource Management Practices on Productivity', American Economic Review, 86, 291-313.

[16] Kaiser, U., 2000, 'New technologies and the demand for heterogeneous labor: firm-level evidence for the German business-related service sector', Economics of Innovation and New Technology, 9, 5, 465-486.

[17] Lindbeck, A. and D. J. Snower, 1996, 'Reorganization of firms and labormarket inequality', American Economic Review, 86, 2, 315-321.

[18] Lindbeck, A. and D. J. Snower, 2000, 'Multi-task learning and the reorganization of work: from Tayloristic to holistic organisation', Journal of Labor Economics 18, 353-376.

[19] Lynch, L. M. and S. E. Black, 1995, 'Beyond the incidence of training: Evidence from a national employers survey', NBER working paper, 5231.

[20] OECD, 1999, 'New enterprise work practices and their labor market implications', Employment Outlook, 179-221. Paris.

[21] Osterman, P., 2000, 'Work Reorganization in an Era of Restructuring: Trends in Diffusion and Effects on Employee Welfare', Industrial and Labour Relations Review, 53, 2, 179-196.

[22] Roberts, M. J. and E. Skoufias, 1997, 'The long-run demand for skilled and unskilled labor in Colombian manufacturing plants', Review of Economics and Statistics, 79, 2, 333-334.

[23] Snower, D. J. 1999, 'The Organizational Revolution and its Labor Market Implications', Keynote address at the European Association of Labour Economists (EALE), Regensburg. 